\title{
VULNERABILITY OF ART WORKS TO BLAST HAZARD: THE FOUNTAIN OF NEPTUNE IN FLORENCE
}

\author{
Marco Domaneschi ${ }^{1}$, Marco Tanganelli ${ }^{2}$, Stefania Viti ${ }^{2}$ and Gian Paolo Cimellaro ${ }^{1}$ \\ ${ }^{1}$ Department of Structural, Geotechnical and Building Engineering (DISEG), Politecnico di Torino, \\ Corso Duca degli Abruzzi 24, 10129 Torino \\ e-mail: \{marco.domaneschi,gianpaolo.cimellaro\}@polito.it \\ ${ }^{2}$ Department of Architecture (DIDA), University of Florence, \\ via della Mattonaia 14, 50121 Firenze \\ \{marco.tanganelli,stefania.viti\}@unifi.it
}

\begin{abstract}
Conservation and protection of art works is a primary goal of each community, since artifacts represent a fundamental cultural and economic asset. In most cases, art goods are exhibited in Museums, which are appointed for their protection. Some of them, however, are exhibited outdoor, since they are conceived and made to enrich the public areas. In these cases, the art goods result to be even more vulnerable, since they are subjected both to natural hazard (i.e. earthquakes and floods) and to vandalic attacks. Art works have an intrinsic vulnerability, due to their irregular shape, slenderness, fragility and to their oldness. This paper is focused on the dynamic response of statues to blast explosion; a valuable case-study, i.e. the Fountain of Neptune, located in "Piazza della Signoria", in Florence. The Fountain of Neptune is a marble and bronze opus made by Bartolomeo Ammannati between 1560 and 1565. The main character of the Fountain, Neptune, is a marble statue 5.7 meters tall, with a weight equal to 11.5 ton. A preliminary laser scanner survey has been made to achieve the geometrical representation of the statue. The geometrical model has been arranged, in order to be used for structural analyses. A numerical analysis has been performed to find the dynamic response of the statue to the loading resulting from a blast explosion. Such response has been found by assuming the explosion of assigned amounts of TNT. Some different cases have been considered, and a limit loading condition has been found for the blast, as a function of its amount.
\end{abstract}

Keywords: Blast loading; artifacts preservation; art works reliability; seismic vulnerability; multi-hazard analysis 


\section{INTRODUCTION}

Artifacts are the focus of the artistic and cultural identity of a country. Despite their fundamental importance, their safety, usually, is not adequately pursued. Different hazard, both natural and human-induced, can threaten the art goods [1]. Furthermore, they are usually very vulnerable, due to their geometrical features (in-plan and in-elevation irregularity, slenderness) their age, and the possible fragility of their material.

Marble sculptures result to be very vulnerable to overturning, due to their high mass and the fragility of the material. Furthermore, the marble sculptures can be very tall, to take advantage of the strength of the material, with a consequent high slenderness. For this reason, many studies have been made on their vulnerability to overturning, with a special attention to the seismic excitations [2-4].

The analysis has been performed on a case-study, i.e. the main sculpture of the Fountain of Neptune, in Florence. It is a marble and bronze opus made by Bartolomeo Ammannati between 1560 and 1565 [5]. The main sculpture of the Fountain, Neptune, is 5.7 meters tall, and it has a weight equal to 11.5 ton.

The explosion has been assumed to be caused by the blast of fixed amounts of TNT, compatible to a vandalic or terroristic attack. The response of the statue to the assumed blast has been checked through Finite Element analysis.

The FE methods have been largely developed in these last years [6,7], even thanks to the outstanding developments occurred in the digital survey, with the consequent improvement of the artifact modelling [8,9], and the increasing availability of computational resources.

In this study, the FE model used for the analysis has been arranged on the basis of a very detailed geometrical model defined after a laser-scanner survey, which provided a pointscloud of the Fountain. The geometrical model described the lateral surface of the manufact; it has been arranged in order to represent the volume of the manufact, and simplified, in order to limit the number of tetragons constituting the model, and the main geometrical irregularities.

The analysis has been performed along the "weakest" direction of the sculpture, i.e. the direction with its lowest lateral stiffness. Different amounts of TNT have been considered to find the limit capacity of the sculpture to blast attacks.

\section{THE CASE-STUDY}

\subsection{The Neptune Fountain}

The Fountain of Neptune, placed in Florence in Piazza della Signoria, was made by Bartolomeo Ammannati between 1560 and 1565 [5,10] after the commitment of Cosimo I de' Medici.

The Fountain, shown in Figure 1a, consists of many different parts, made in marble and bronze; the main sculpture, representing Neptune, is placed on a central pedestal representing a horse-drawn cart placed in an octagonal basin, a space further decorated with statues of Scylla and Charybdis; all around, some minor marble and bronze sculptures were added, representing river gods, satyrs and sea-horses. Some of the sculptures currently constituting the Fountain are copies made the XIX century, to preserve the original artifacts from vandalism. Indeed, from its construction, the Fountain experienced many vandalic actions. The first documented damage dates back to 1580, and many other damaged were made along the centuries; the last event occurred in 2005, when three vandals climbed Neptune, damaging one hand and the trident of the sculpture. 
a. The Fountain of Neptune

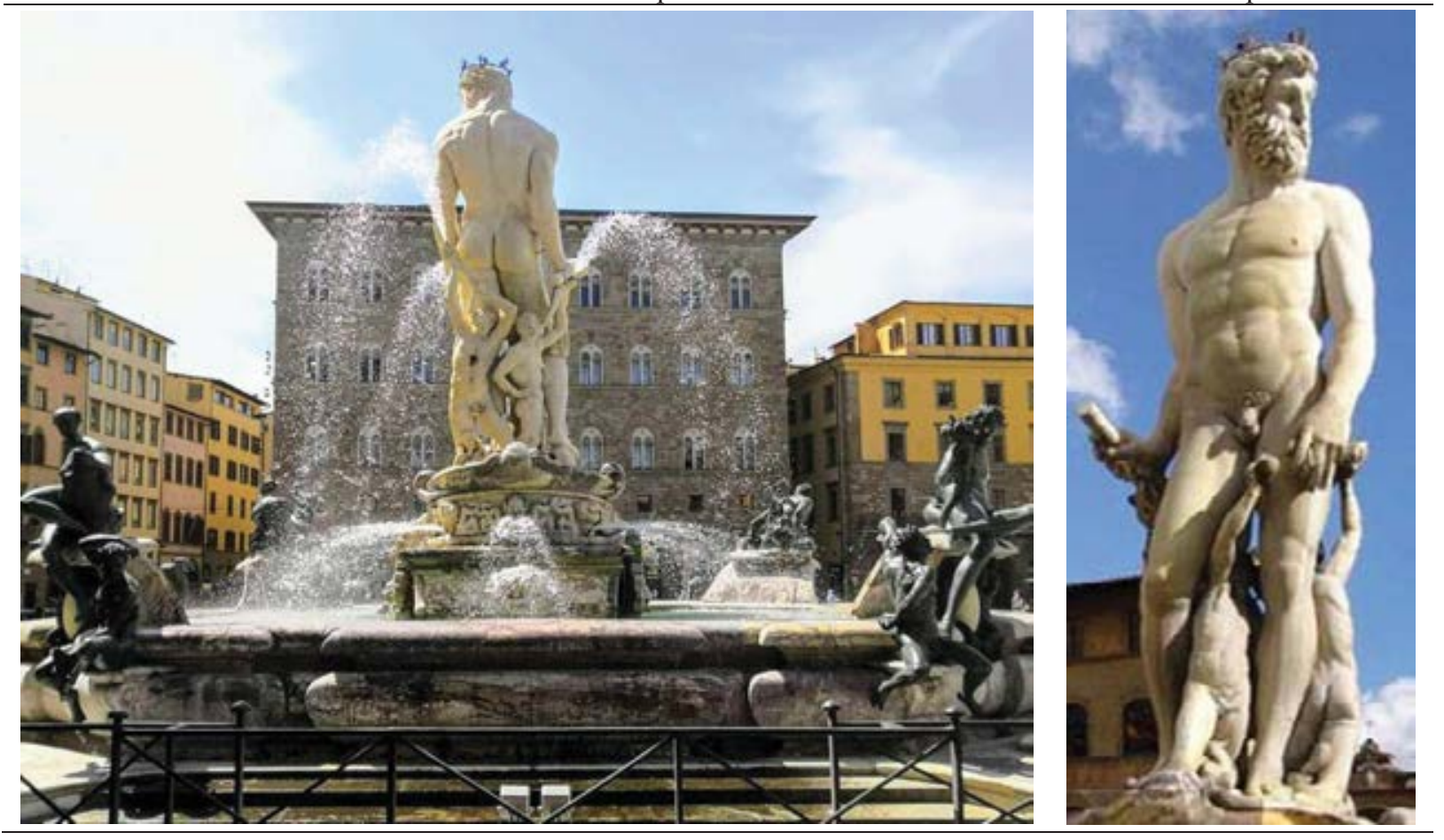

Figure 1. The Fountain of Neptune

\subsection{The statue of Neptune}

The main character of the Fountain, Neptune, is a marble statue 5.7 meters tall (see Figure 1b), with a weight equal to 11.5 ton. The marble used for the sculpture has been taken by a Carrara quarry. The mechanical properties assumed in the work, listed in Table 1, have been found through an experimental survey made on samples of marble similar to the one used for the statue $[11,12]$. A special attention has been paid to the value to assume for the friction coefficient $[13,14]$, which plays an important role in the prediction of the collapse mode of the sculptures under horizontal excitations.

Table 1. Mechanical properties of the marble

\begin{tabular}{lll}
\hline Density & {$\left[\mathrm{kg} / \mathrm{m}^{3}\right]$} & 2700 \\
\hline Young Modulus & {$[\mathrm{MPa}]$} & 50000 \\
\hline Poisson coefficient & {$[\mathrm{MPa}]$} & 0.2 \\
\hline Compressive strength & {$[\mathrm{MPa}]$} & 50 \\
\hline Tensile strength & {$[\mathrm{MPa}]$} & 5 \\
\hline Friction coefficient & - & 0.8 \\
\hline
\end{tabular}

\subsection{The structural model}

The structural model of Neptune has been made on the basis of a geometrical survey made on the Fountain of Neptune, made through laser-scanner. The geometrical survey provided a points-cloud, which has been used to find the geometrical model consisting of a detailed lateral surface described through 1234492 polygons [15]. Such geometrical model has been deeply simplified to obtain the structural model to use for the dynamic analysis, made of a lower number of polygons. Besides being simplified (the number of polygons of the lateral surface of the model has been reduced to 29000), the model has been changed by a "surface" 
to a solid one; finally, a model made of 152000 tetragons has been obtained. Figure 2 shows the various steps of the modeling procedure.

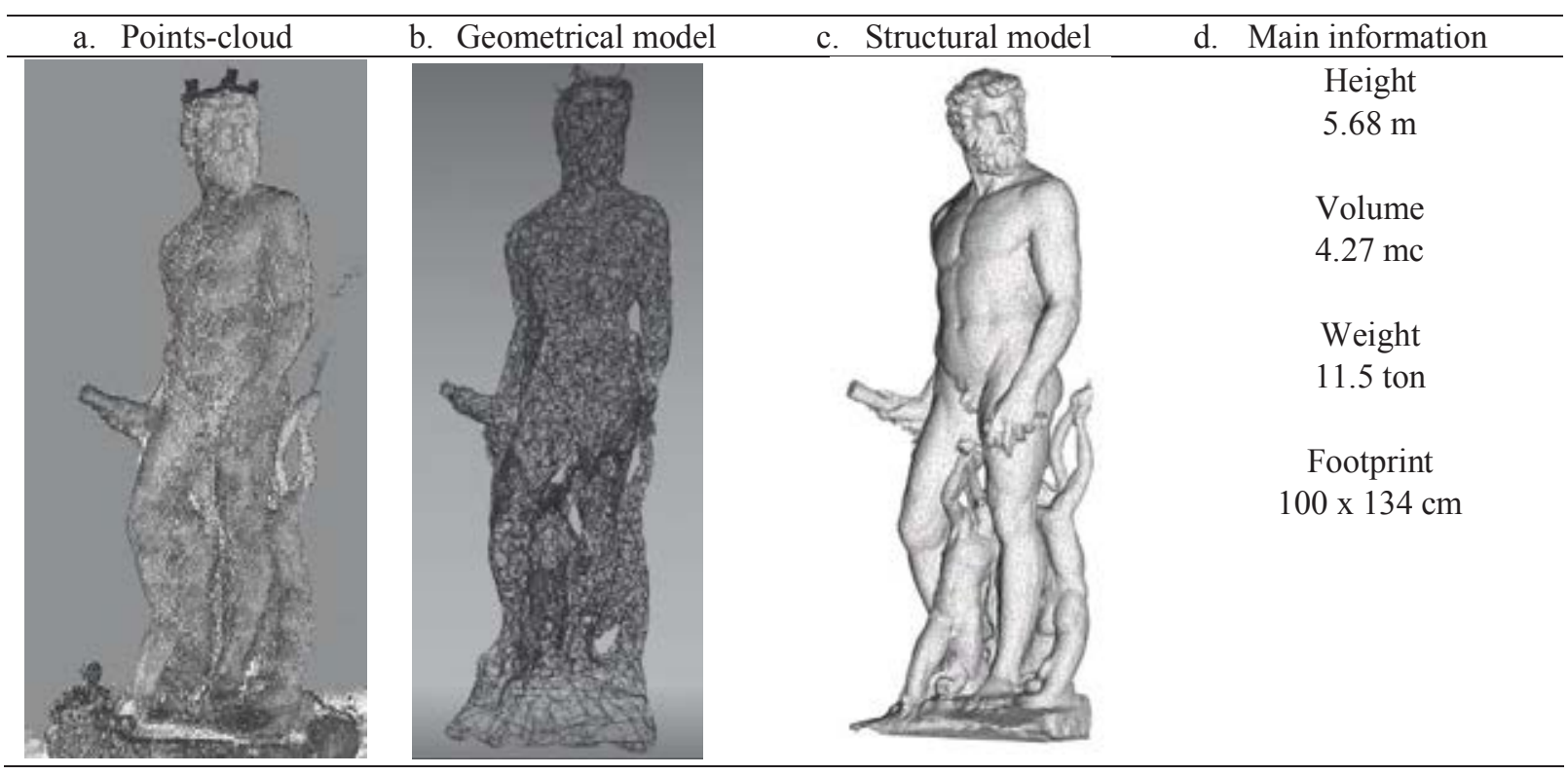

Figure 2. Geometrical and structural models.

\section{THE BLAST ACTION}

The loading acting to the sculpture as an effect of the blast has been assumed equal to the reflecting pressure, which has been determined according to the empirical approach $[16,17]$ based on the Kingery and Bulmash [18] contribution.

The pressure applied to the statue surface has been quantified as a function of the normal reflected pressure peak, $P_{r 0}$, defined as a function of the Hopkinson-Cranz scaled distance $Z$, as provided by Karlos and Solomos [19]:

$$
Z=\frac{R}{W^{1 / 3}}
$$

where $W$ is the assumed charge mass (expressed in metric tons) and $R$ is the distance (expressed in meters) of the target surface from the center of the blast. The quantity has been found through the equation (2), according to [16].

$$
P_{r 0}(Z)=\left(1+\frac{1}{2 e^{10 Z}}\right) \exp \left[2.0304-1.8036 \ln Z-0.09293 \ln ^{2} Z-0.8779 \sin (\ln Z)-0.3603 \sin ^{2}(\ln Z)\right]
$$

After the peak, the pressure wave presents a degrading wave phase [16] of duration $t_{0}$, which ends with the zeroing of the pressure (positive phase), and a further phase characterized by the negative sign of the overpressure (negative phase). There are various expressions to describe the reflected pressure, such as has the modified Friendlander equation [20], based on the Heaviside function. In this work, however, a simplified approach has been adopted, and the trend of the pressure in the positive phase has been assumed as triangular, with an effective positive duration, $t_{0}$, quantified through the expressions proposed by Vannucci et al. [21]:

$$
t_{0}(Z)=t_{0 w} W^{\frac{1}{3}}
$$

as a function of the scaled positive duration, $t_{0 w}$, quantified through the equation (4). 


$$
\begin{aligned}
t_{0 w}(Z, W)=\exp \left\{0.592+2.913 \ln Z-1.287 \ln ^{2} Z-1.788 \ln ^{3} Z+1.151 \ln ^{4} Z+0.325 \ln ^{5} Z-0.383 \ln ^{6} Z\right. \\
+0.090 \ln ^{7} Z-0.004 \ln ^{8} Z-0.0004 \ln ^{9} Z \\
\left.+0.537 \cos ^{7}[1.032(\ln Z-0.059)] \sin [1.088(\ln Z-2.023)]\right\}
\end{aligned}
$$

In this work, two different cases of analysis have been made, differing from each other for the assumed amount of TNT, respectively equal to $10 \mathrm{~kg}$ and to $50 \mathrm{~kg}$; both cases are compatible to the quantities compatible to vandalism actions [22]. The placement of the explosive has been assumed equal to $8.8 \mathrm{~m}$ from the statue, i.e. along the external fence. In Table 2 the main data describing the blast loading have been listed.

Table 2. Main data regarding the blast loading.

\begin{tabular}{lccc}
\hline Quantity & {$[$ unit] } & case \#1 & case \#2 \\
\hline Mass of TNT, $W$ & {$[\mathrm{~kg}]$} & 10 & 50 \\
\hline Distance, $R$ & {$[\mathrm{~m}]$} & 8.8 & 8.8 \\
\hline Scaled distance, $Z$ & {$[\mathrm{~m}]\left[\mathrm{kg}^{-1 / 3}\right]$} & 4.08 & 2.39 \\
\hline normal reflected pressure peak, $P_{r 0}$, & {$[\mathrm{MPa}]$} & 0.1676 & 0.6029 \\
\hline Scaled positive duration $\left(t_{0}\right)$ & {$[\mathrm{ms}]\left[\mathrm{kg}^{-1 / 3}\right]$} & 3.53 & 2.25 \\
\hline Effective positive duration $\left(t_{0 w}\right)$ & {$[\mathrm{ms}]$} & 7.62 & 8.30 \\
\hline
\end{tabular}

\section{THE ANALYSIS}

\subsection{The preliminary investigations}

Some preliminary investigations have been made before performing the dynamic analysis. The analyses have been made by assuming the TNT placed along the direction with the minimum inertia of the statue, as shown in Figure 3; furthermore, the pedestal of the statue has not been included in the analysis. Indeed, due the position of the statue within the Fountain, the pedestal is not fully involved by the pressure wave induced by the explosion (see Figure 4).

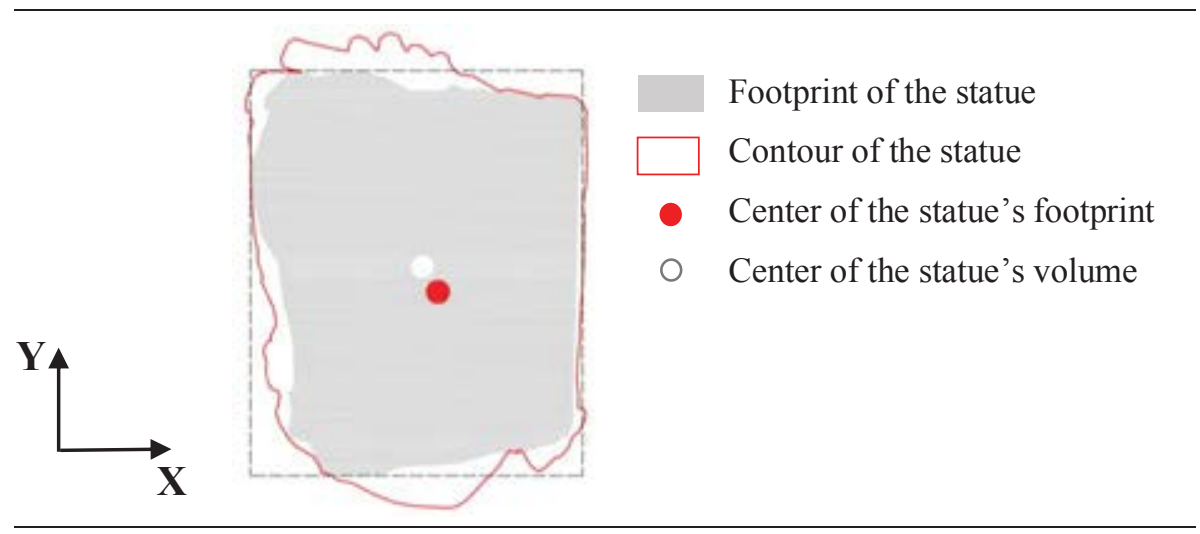

Figure 3. Direction of analysis of the sculpture

First of all, a modal analysis has been made through the software Marc \& Mentat [23] to check the dynamic properties of the statue. The results of the modal analysis, in terms of frequencies and correspondent shapes, have been shown in Figure 5. The Fundamental period found for the sculpture is equal to $0.081 \mathrm{sec}$, compatibly to the ones found for similar statues [3]. As can be seen, the first mode is mostly translational, along the $X$ direction, whilst the following ones have a relevant rotational response. 


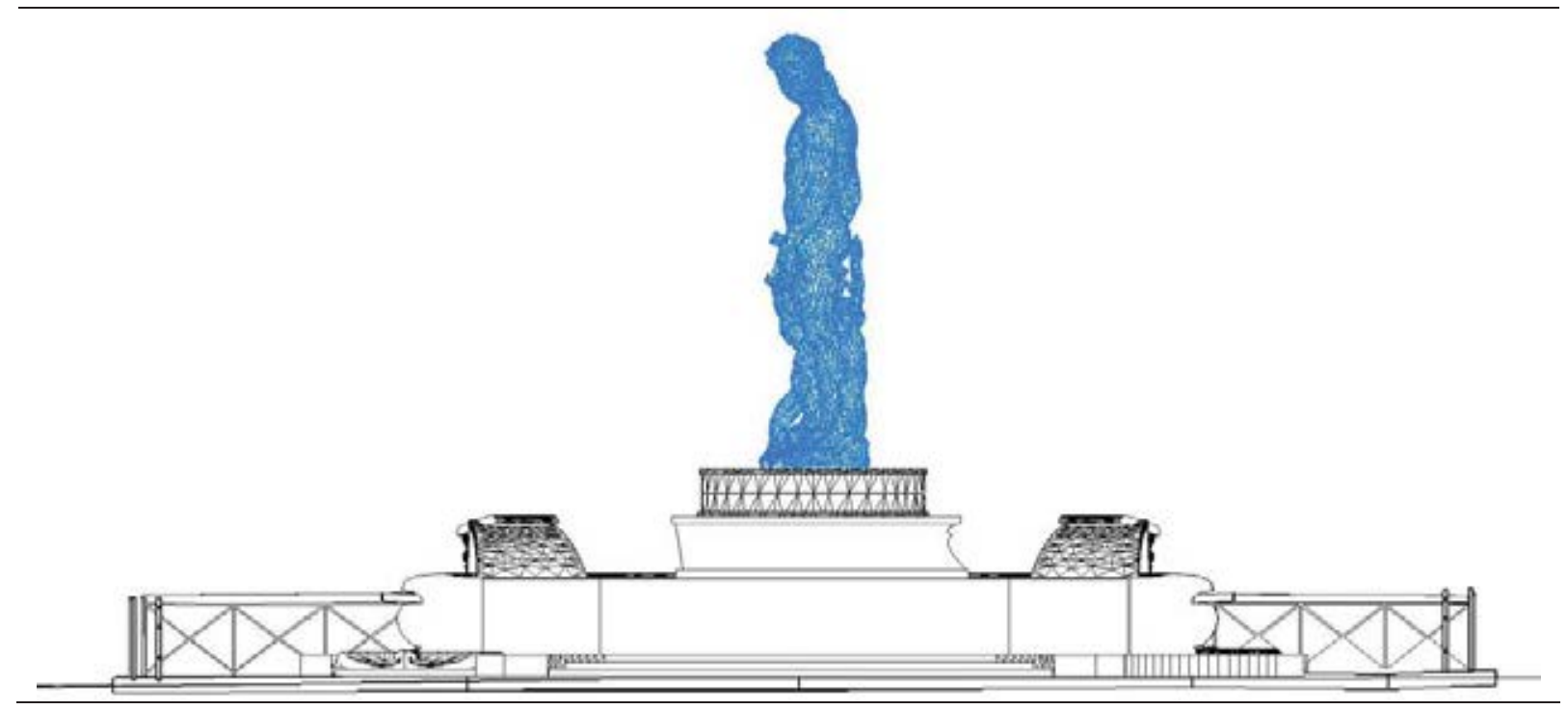

Figure 4. Position of the sculpture within the Fountain
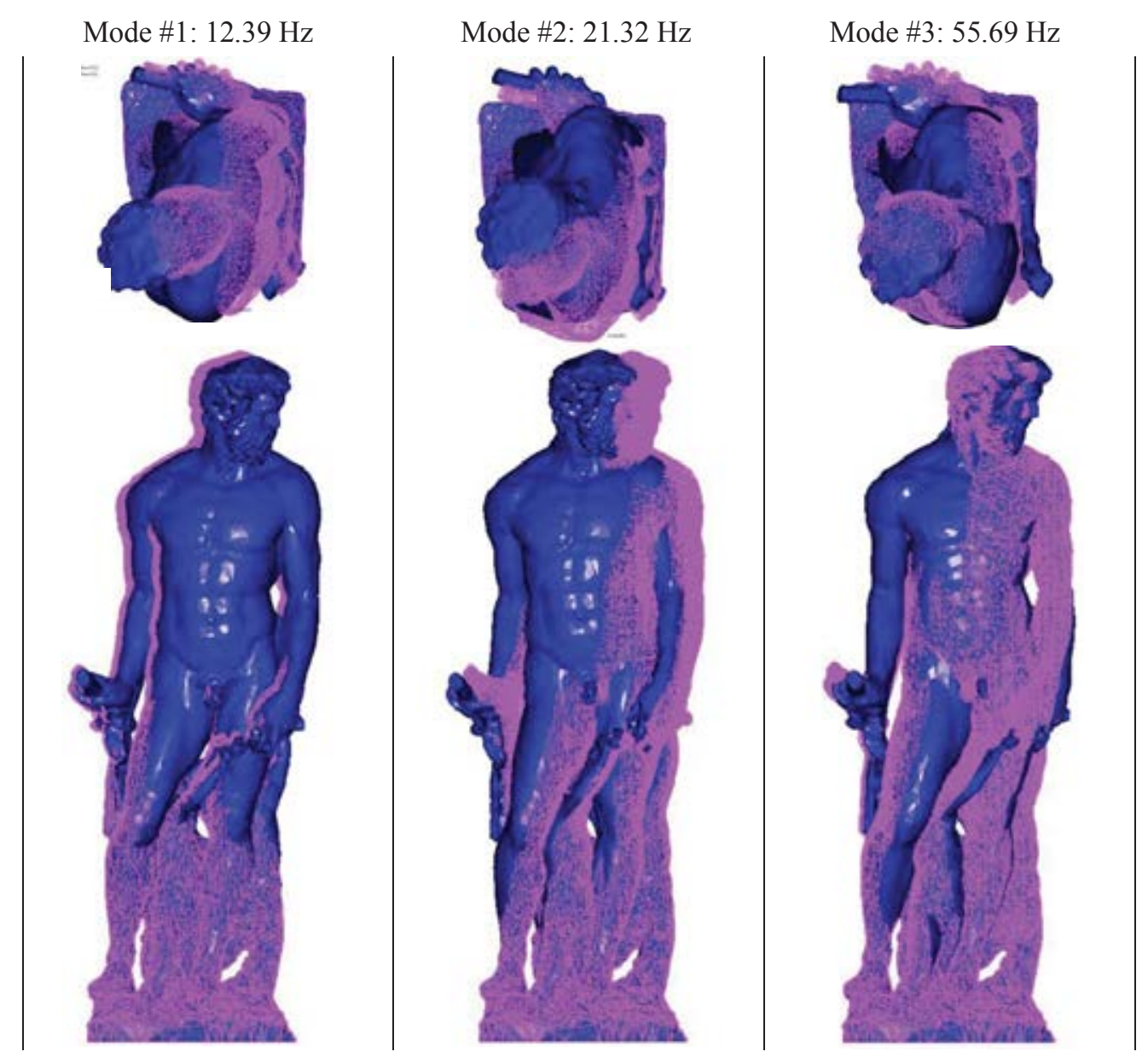

Figure 5. Modal shapes of Neptune.

The level of stress in the material as an effect of the gravitational loads has been checked by performing a linear elastic analysis; the maximum stress achieved in the sculpture at its base (see Figure 6) is equal to about $1.35 \mathrm{MPa}$, well below the limit value of the material. 
Furthermore, the limit conditions in terms of top displacement $\left(d_{\text {lim }}=1.38 \mathrm{~m}\right)$ for the overturning (see Figure 7) have been found. The limit top displacement has been found by imposing the gravitational load of the sculpture center at the limit of the inertial core of the sculpture print.

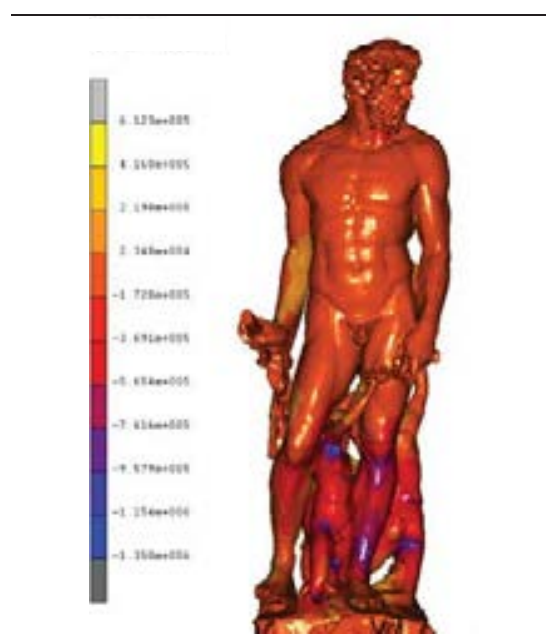

Figure 6. Maximum stress (Pa) under gravitational loads

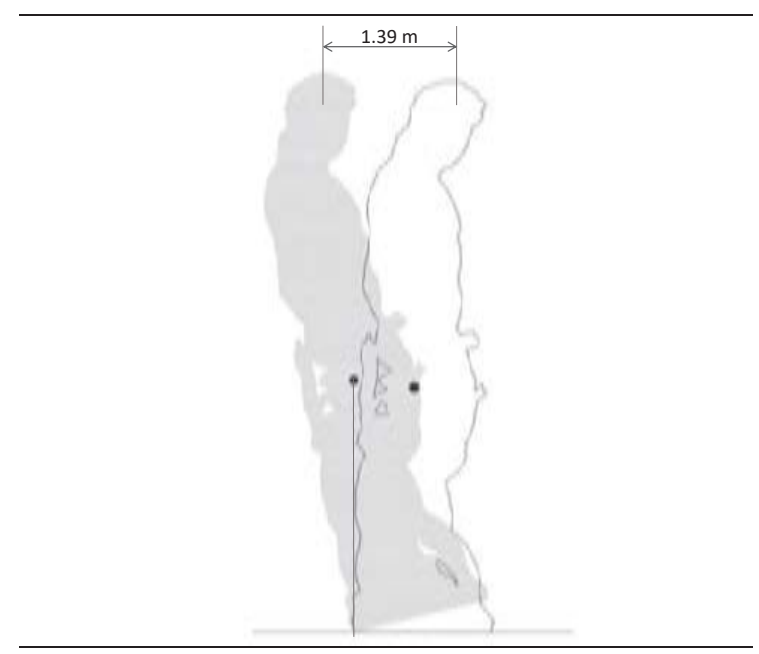

Figure 7. Top displacement at the overturning

The horizontal force corresponding to the overturning, instead, has been found by equalizing the capacity moment to the moment of demand. The moment of capacity is defined as the product of the gravitational load, supposed to be applied to the centroid of the volume and the distance between the centroid and the turning point of the basement; the moment of demand, instead, is defined as the product of the horizontal force - supposed to be applied to the statue centroid - and its distance to the turning point, i.e. the height of the statue centroid, $h$. This simplified analysis has been made by representing the sculpture as a rigid body simply supported on the pedestal.

\subsection{The dynamic analysis}

The response of the case-study to the considered blast excitation has been found by performing a dynamic analysis through the Finite Element model described in $\S 2.3$ through the software Marc \& Mentat [23]. The duration of the positive pressure wave is very short, so that the blast can be assumed as instantaneous loading. In the numerical simulation, the blast occurs at the time $t=1 \mathrm{sec}$, after the application of the static (gravitational) load. The response of the system to the blast loading has been checked for further 9 seconds, as shown in Figure 8 .

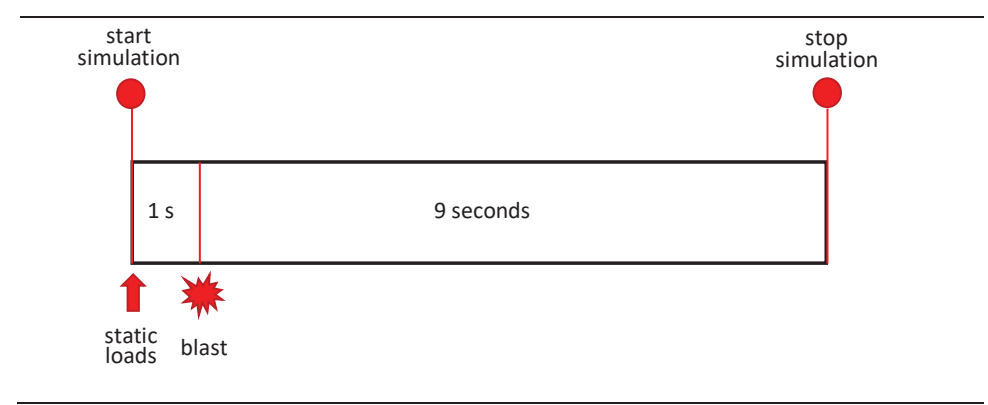

Figure 8. Duration of the analysis and loads timing. 
The base restraint has been assumed to be as a simple support, with a friction coefficient between the contact surfaces equal to 0.8 , to account for probable roughness of the surfaces and the presence of mortar. The top displacement of the sculpture, i.e. the displacement at the top of the head of the sculpture, has been compared to the displacement experienced by the two extremes (front and back) of its base. Figures 9 and 10 show the displacement histories found for the two assumed quantities of explosive.

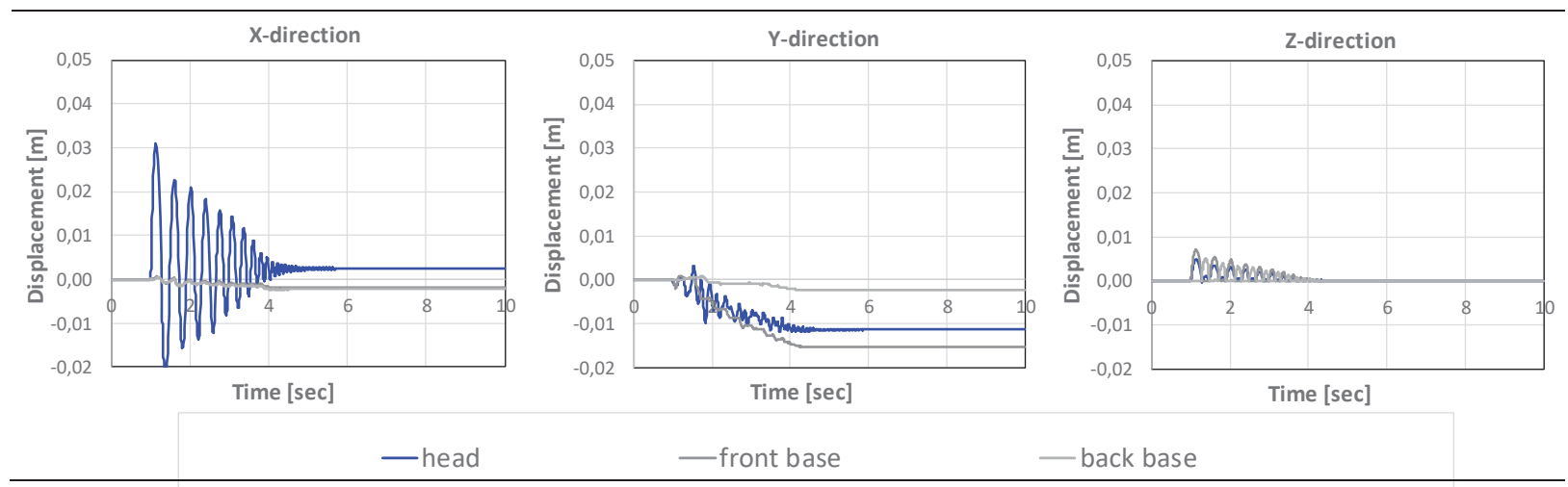

Figure 9. Displacements histories for the case \# $1(W=10 \mathrm{~kg})$

As can be noted, for the blast induced by $10^{10} \mathrm{~kg}$ of TNT (Figure 9), the maximum top displacement, recorded along the $X$-direction, is around $3 \mathrm{~cm}$, much lower than the overturning limit of the statue. The sculpture exhibits a rocking response, with a different period in the two directions. The dynamic response sculpture of the sculpture is almost symmetric in the $X$ direction, whilst it is strongly non-symmetric along the $Y$-direction. In both cases, after the rocking the sculpture settles in a different equilibrium asset.

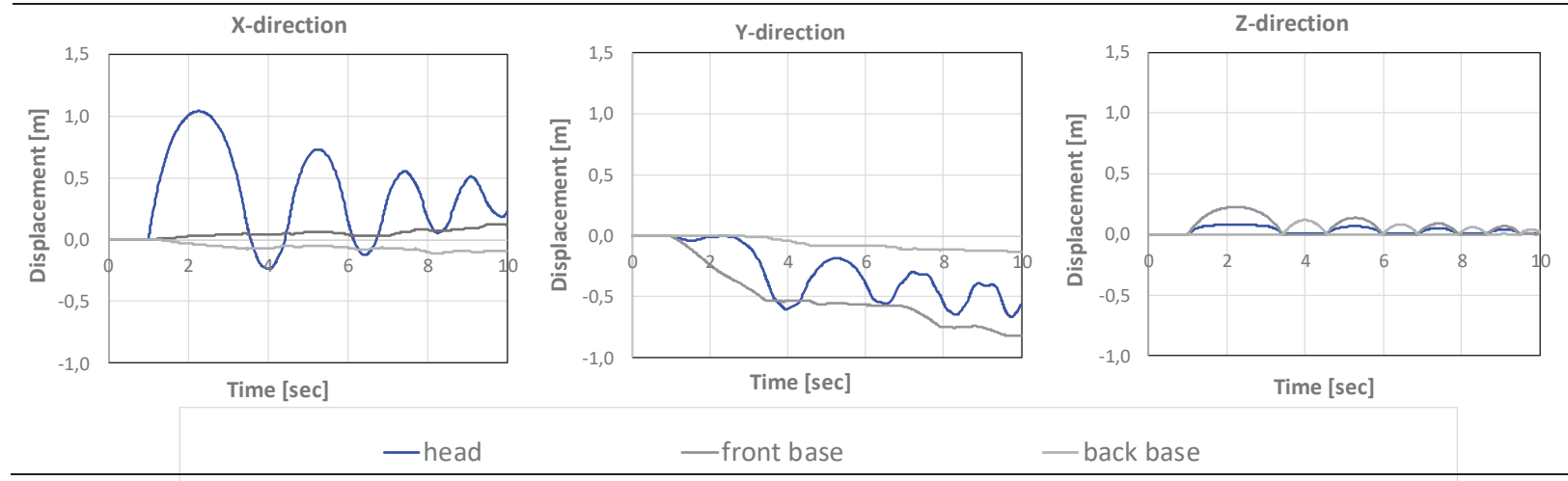

Figure 10. Displacements histories for the case \# $2(W=\mathbf{5 0} \mathbf{~ k g})$

When the higher loading condition is considered (Figure 10), the maximum displacement achieved by the sculpture head overcomes 1 meter, resulting close to the overturning limit found according to the simplified static analysis. Even in this case, the sculpture exhibits a symmetric response along the $X$-direction, differently from the $Y$-direction. The rocking has a period much larger than in the other cases (around 2 seconds), similar for the two directions.

In this case, the system does not achieve a different equilibrium within the duration of the analysis; it should be underlined, however, that no damping has been introduced in the analysis. 


\section{CONCLUSIONS}

In this paper the capacity of the main sculpture of the Fountain of Neptune in Florence has been checked with reference to an explosion due different amounts of TNT, respectively equal to $10 \mathrm{~kg}$ and to $50 \mathrm{~kg}$. Before performing the dynamic analysis of the statue under the assumed blast conditions, some preliminary analyses have been carried, to check the dynamic properties of the sculpture, its limit condition to overturning and the static response under gravitational loads only.

The dynamic response of the statue under the assumed blast cases has been found by performing a nonlinear dynamic analysis on a very detailed FE model. The structural model has been set on the basis of a detailed laser-scanner survey, by arranging the geometrical model, starting from the points-cloud.

The analysis evidenced a rocking response of the statue along the $X$-direction, accordantly to results provided by the modal analysis. The dynamic response of the statue shows even a torsional behavior, which can be noted by observing the displacement histories of its base points along the $Y$-direction. The torsional response of the system becomes even more evident at the increasing of the assumed loading intensity. The blast due to the higher amount $(50 \mathrm{~kg})$ induces on the system a dynamic response close to its capacity; the maximum top displacement overcomes 1 meter along the $X$-direction, whilst along the $Y$-direction the system does not find a new static equilibrium within the analysis duration.

Further analyses should be made to check the role of the blast position on the statue response, and to assess the best possible restraint condition to minimize the vulnerability of the sculpture.

\section{REFERENCES}

[1] Reinhorn AM, Viti S (2020). Monumental buildings used as museums: Protection or danger for the artifacts? Procedia Structural Integrity Vol. 29: pp. 40-47.

[2] Berto L, Favaretto T, Saetta A, Antonelli F, Lazzarini L (2012). Assessment of seismic vulnerability of art objects: The "Galleria dei Prigioni" sculptures at the Accademia Gallery in Florence, JCH, 13, 7-21.

[3] Viti S, Pintucchi B, Rotunno T, Tanganelli M (2020). The seismic analysis of Cerere at the Museum of Bargello. Bulletin of Earthquake Engineering, https://doi.org/10.1007/s10518-020-00802-6.

[4] Pintucchi B, Rotunno T, Tanganelli M, Viti S (2019). Bartolomeo Ammannati's Fountain: comparisons between different numerical models. RILEM Bookseries - Structural Analysis of Historical Constructions. Aguilar, R., Torrealva, D., Moreira, S., Pando, M., Ramos, L.F. (Eds.) Springer International Publishing, p. 1201-1209.

[5] Carlo Cresti (1982). Le fontane di Firenze, Firenze, Bonechi, pp. 26-37.

[6] Pascale G, Lolli A. (2015) Crack assessment in marble sculptures using ultrasonic measurements: Laboratory tests and application on the statue of David by Michelangelo. JCH vol. 16 (6), 813-821.

[7] Sorace S, Terenzi G. (2015) Seismic performance assessment and base-isolated floor protection of statues exhibited in museum halls, Bull Earthquake Eng, 13, 1873-1892.

[8] Bagnéris M, Cherblanc F, Bromblet P, Gattet E, Gügi L, Nony N, Mercurio V, Pamart A (2017). A complete methodology for the mechanical diagnosis of statue provided by innovative uses of 3D model. Application to the imperial marble statue of Alba-laRomaine (France). Journal of Cultural Heritage, 28:109-116. 
[9] Forcellini D, Giardi F, Tanganelli M (2019). Seismic assessment of the historical third tower in San Marino based on a 3D laser scanner survey (3D-LSS). Innovative Infrastructure Solutions, 4 (1), art. no. 20.

[10] Cristina Acidini Luchinat (1995). Bartolomeo Ammannati artefice di fontane, in "Bartolomeo Ammannati scultore e architetto, 1511-1592", a cura di Niccolò Rosselli del Turco e Federica Salvi, Atti del Convegno di Studi (Firenze-Lucca, 17-19 marzo 1994), Firenze, Alinea, pp. 31-40.

[11] Tanganelli M, Coli M, Cimellaro GP, Marasco S, Cardoni A, Noori AZ, Viti S (2019). Dynamic analysis of artifacts: experimental tests for the validation of numerical models. In: National Technical University of Athens (NTUA), Proceedings of the 7th International Conference on Computational Methods on Structural Dynamics and Earthquake Engineering. vol. 2, p. 2865-2877, M. Papadrakakis, M. Fragiadakis, ISBN: 978-61882844-7-0, Crete, Greece, 24-26/6/2019.

[12] Viti S, Tanganelli M (2019). Resimus: A research project on the seismic vulnerability of museums' collections. In: (a cura di): M. Papadrakakis M. Fragiadakis, COMPDYN Proceedings. vol. 2, p. 2819-2829, National Technical University of Athens, ISBN: 978618-82844-7-0, grc, 2019.

[13] Monaco M, Guadagnuolo M, Gesualdo A. (2014). The role of friction in the seismic risk mitigation of freestanding art objects. Nat Hazards, 73:389-402.

[14] Domaneschi M, Tanganelli M, Viti S, Cimellaro GP (2020). Developing a laboratory facility to assess friction coefficients of standing samples. PROCEDIA STRUCTURAL INTEGRITY, vol. 29, p. 142-148, ISSN: 2452-3216, doi: 10.1016/j.prostr.2020.11.150

[15] Domaneschi M, Tanganelli M, Viti S, Cimellaro GP (2020). Damage risk assessment of historical asset using laser scan and finite element. PROCEDIA STRUCTURAL INTEGRITY, vol. 29, p. 183-191, ISSN: 2452-3216, doi: 10.1016/j.prostr.2020.11.155

[16] Masi F, Stefanou I, Vannucci P, Maffi-Berthier V (2020). Resistance of Museum artefacts against blast loading. Journal of Cultural Heritage 44: 163-173.

[17] Larcher M, Casadei F (2010). Explosions in complex geometries: a comparison of several approaches. International Journal Protective Structures 1 (2): 169-195.

[18] Kingery CN, Bulmash G (1984). Technical Report Arbrl-tr-02555: Air Blast Parameters from Tnt Spherical Air Burst and Hemispherical Burst, U.S. Army Ballistic Research Laboratory, Technical Report.

[19] Karlos V, Solomos G (2013). JRC - European Commission, "Calculation of Blast Loads for Application to Structural Components. Administrative Arrangement No JRC 322532011 with DG-HOME Activity A5 - Blast Simulation Technology Development.

[20] Friedlander FG (1946). The diffraction of sound pulses. I. Diffraction by a semi-infinite plate. Proc. R. Soc. Lond. A (186): 322-344

[21] Vannucci P, Masi F, Stefanou I (2017). A study on the simulation of blast actions on a monumental structure, hal-01447783v3.

[22] Crime Prevention and Security Management in Museum, De Luca Editori D'Arte.

[23] MARC \& MENTAT (2014). Release 2014.2.0, MSC Software Corporation, Santa Ana, California, USA 